\title{
Development of an Extreme High Temperature n-type Ohmic Contact to Silicon Carbide
}

\author{
Laura J Evans ${ }^{1, a}$, Robert S Okojie ${ }^{1, b}$, and Dorothy Lukco ${ }^{2, c}$ \\ ${ }^{1}$ NASA Glenn Research Center, 21000 Brookpark Road, M/S 77-1, Cleveland, Ohio 44135, USA \\ ${ }^{2}$ ASRC Aerospace Corporation, NASA Glenn Research Center, 21000 Brookpark Road, M/S 77-1, \\ Cleveland, Ohio 44135, USA \\ alaura.j.evans@nasa.gov, brobert.s.okojie@nasa.gov, 'dorothy.lukco-1@nasa.gov
}

Keywords: silicon carbide, ohmic contact, high temperature, tungsten, nickel

\begin{abstract}
We report on the initial demonstration of a tungsten-nickel (75:25 at. \%) ohmic contact to silicon carbide ( $\mathrm{SiC}$ ) that performed for up to fifteen hours of heat treatment in argon at $1000{ }^{\circ} \mathrm{C}$. The transfer length method (TLM) test structure was used to evaluate the contacts. Samples showed consistent ohmic behavior with specific contact resistance values averaging $5 \times 10^{-4} \Omega-\mathrm{cm}^{2}$. The development of this contact metallization should allow silicon carbide devices to operate more reliably at the present maximum operating temperature of $600{ }^{\circ} \mathrm{C}$ while potentially extending operations to $1000{ }^{\circ} \mathrm{C}$.
\end{abstract}

\section{Introduction}

Silicon Carbide ( $\mathrm{SiC}$ ) is widely recognized as one of the materials of choice for high temperature, harsh environment sensors and electronics due to its ability to survive and continue normal operation in such environments [1]. Sensors and electronics in SiC have been developed that are capable of operating at temperatures of $600{ }^{\circ} \mathrm{C}$. However operating these devices at the upper reliability temperature threshold increases the potential for early degradation. Therefore, it is important to raise the reliability temperature ceiling higher, which would assure increased device reliability when operated at nominal temperature. There are also instances that require devices to operate and survive for prolonged periods of time above $600{ }^{\circ} \mathrm{C}[2,3]$. This is specifically needed in the area of hypersonic flight where robust sensors are needed to monitor vehicle performance at temperature greater than $1000{ }^{\circ} \mathrm{C}$, as well as for use in the thermomechanical characterization of high temperature materials (e.g. ceramic matrix composites). While $\mathrm{SiC}$ alone can withstand these temperatures, a major challenge is to develop reliable electrical contacts to the device itself in order to facilitate signal extraction.

\section{Experimental}

Two to three $\mu \mathrm{m}$ thick homoepitaxial layers with nitrogen doping levels of 5-7 $\times 10^{18} \mathrm{~cm}^{-3}$ were commercially grown by Cree, Inc. on the silicon face of off-axis high-resistivity p-type substrates (4H-SiC with a resistivity of $7.5 \Omega-\mathrm{cm}\left[4.74 \times 10^{17} \mathrm{~cm}^{-3}\right]$ and $6 \mathrm{H}-\mathrm{SiC}$ with a resistivity of $2.4 \Omega-\mathrm{cm}$ $\left.\left[2.65 \times 10^{18} \mathrm{~cm}^{-3}\right]\right)$. The epilayers were patterned into isolated mesas in a parallel-plate reactive ion etcher (RIE) system using $\mathrm{SF}_{6}$ and Ar chemistry and a metal mask (titanium/nickel/aluminum). Metal contacts were deposited onto mesa surfaces prepared by extensive chemical cleaning. A sequence of equal volume $\mathrm{HCl}: \mathrm{HNO}_{3}$, equal volume $49 \% \mathrm{HF}: \mathrm{HNO}_{3}$, and solvent cleaning was used to remove the metal mask and polymer residue introduced during the RIE plasma etch. An equal volume $30 \% \mathrm{H}_{2} \mathrm{O}_{2}: \mathrm{H}_{2} \mathrm{SO}_{4}$ solution was used to remove any remaining organic contamination, followed by wet oxidation and HF strip to remove structural damage.

The contact metallization consisted of a sputtered $1000 \AA$ layer of W (75 at. \%):Ni (25 at. \%), followed by a $200 \AA$ layer of silicon (Si) which is used to prevent premature oxidation of tungsten after chamber venting and during annealing. The contact metals were chosen for their high 
temperature capability, as well as historical results of ohmic behavior with $\mathrm{SiC}[4,5]$. The transfer length method (TLM) test structure, as shown in Fig. 1, was used to evaluate the metal contacts [6, 7]. TLM structures consisted of five rectangular contact pads, with three subsets. Dimensions/(edge-to-edge distances) were $100 \times \quad$ x $40 \quad \mu^{2} /(35,70,105,140 \mu \mathrm{m}), \quad 100 \quad \mathrm{x} \quad 45$ $\mu \mathrm{m}^{2} /(30,60,90,120 \mu \mathrm{m})$, and $100 \times 50 \mu \mathrm{m}^{2} /(25,50,75,100 \mu \mathrm{m})$.

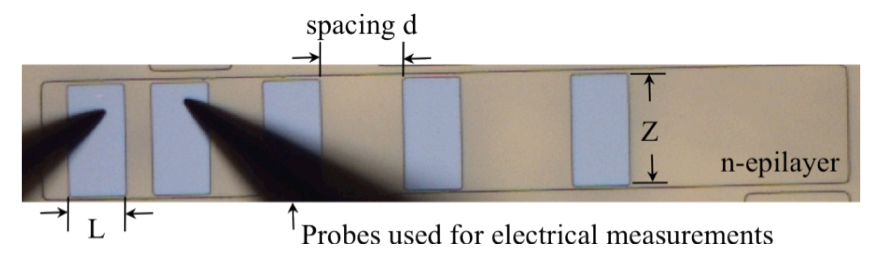

Fig. 1: Optical image of the linear TLM structures used to obtain specific contact resistance values $\left(\rho_{\mathrm{c}}\right)$.

Samples were initially annealed for one hour at $1100{ }^{\circ} \mathrm{C}$ in $5 \mathrm{slpm}$ argon in a tube furnace, and subsequently heated intermittently for several hours at $1000{ }^{\circ} \mathrm{C}$ in argon in the same tube furnace. Room temperature measurements of current-voltage $(\mathrm{I}-\mathrm{V})$ and specific contact resistance $\left(\rho_{\mathrm{c}}\right)$ were made after deposition, first anneal, and after heating for several hours. Sample surfaces were also analyzed using Auger electron spectroscopy (AES) and X-ray diffraction (XRD). A detailed study of the contact metal/SiC interface after fifteen hours of heating was also performed using highresolution transmission electron microscopy (HR-TEM) and energy-dispersive X-ray spectroscopy (EDS).

\section{Results}

All the samples remained consistently ohmic during the entire duration of the heat treatment. The I$\mathrm{V}$ characteristics of the two polytypes as measured immediately after deposition, after the $1100{ }^{\circ} \mathrm{C}$ anneal, and after prolonged treatment at $1000{ }^{\circ} \mathrm{C}$, are shown in Fig. $2 \mathrm{a}$ and b, respectively. The probed contacts in Fig. 2 measured $40 \mu \mathrm{m} \times 100 \mu \mathrm{m}$ with a spacing of $30 \mu \mathrm{m}$. The I-V curves demonstrate the ohmic behavior of the contacts after first exposure to high temperature and that they remain so during the full heat treatment.

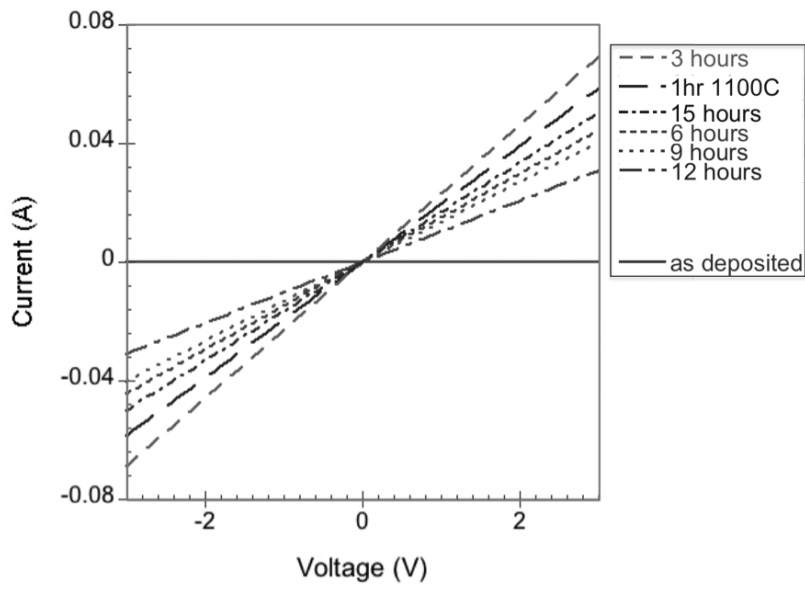

(a)

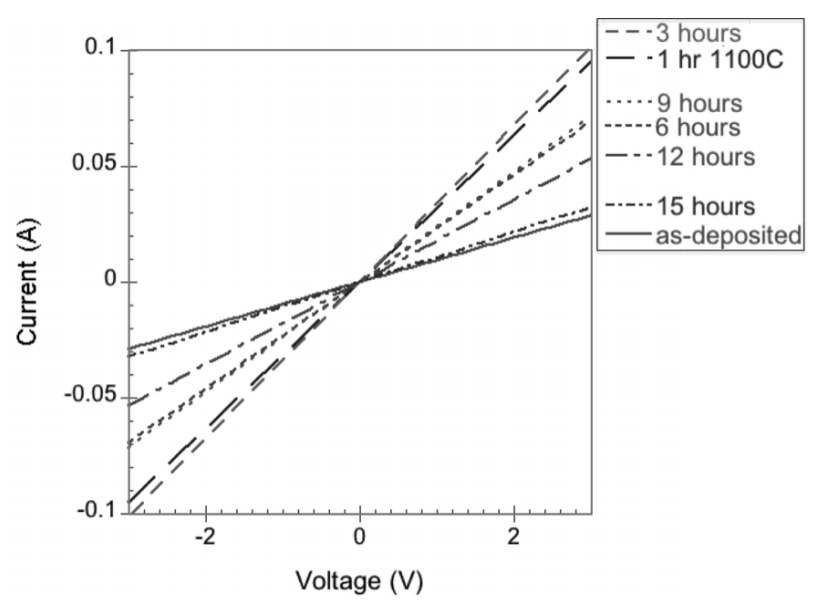

(b)

Fig. 2: Comparison of I-V curves after heating for a n-doped $\mathrm{SiC}$ epilayer $\left(5.3-7.7 \times 10^{18}\right.$ $\mathrm{cm}^{-3}$ ) on (a) $4 \mathrm{H}$ p-type $\mathrm{SiC}$ substrate and (b) $6 \mathrm{H}$ p-type $\mathrm{SiC}$ substrate.

Specific contact resistance, $\rho_{c}$, was measured by averaging across nine $(6 \mathrm{H} \mathrm{SiC})$ and six $(4 \mathrm{H} \mathrm{SiC})$ TLM subsets from each sample. Values were calculated using plots of total resistance $\left(\mathrm{R}_{\mathrm{T}}\right)$ versus spacing (d). The linear transfer length $\mathrm{L}_{\mathrm{T}}$ was extracted from the $\mathrm{x}$-axis intercept, while the contact 
resistance $R_{C}$ was extracted from the y-axis intercept. The sheet resistance $\rho_{s}$ of the epilayer was determined from the slope. Specific contact resistance was then calculated by applying Eq. 1 [7]:

$$
\rho_{\mathrm{c}}=\mathrm{R}_{\mathrm{C}} \mathrm{L}_{\mathrm{T}} \mathrm{Z}
$$

Contact length, $Z$, is as defined in Fig. 1. Figure 3 displays specific contact resistance values obtained after heating for various lengths of time. The contact resistance values were initially observed to be high in the first couple of hours, but decreased and remained stable thereafter. The final $\rho_{\mathrm{c}}$ measured after 15 hours at $1000{ }^{\circ} \mathrm{C}$ was $5 \times 10^{-4} \Omega-\mathrm{cm}^{2}$ for both $4 \mathrm{H}$ and $6 \mathrm{H}$ substrates. This value compares reasonably with other contact schemes on similar polytype and doping levels commonly found in literature [8], with the added advantage of an extended temperature range.

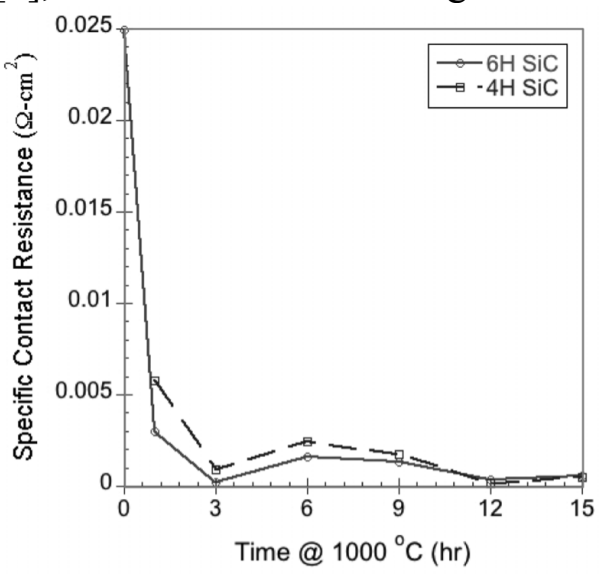

Fig. 3: Specific contact resistance of metallization on 5-7 x $10^{18} \mathrm{~cm}^{-3} \mathrm{n}$-doped SiC epilayers after prolonged heating at $1000^{\circ} \mathrm{C}$.

In addition to the electrical characterization, the metal contacts were also analyzed by AES depth profiles in order to get a better understanding of the zonal reactions, intermetallic diffusion, and the roles they play in the stability of the electrical behavior at such extreme temperatures. Fig. 4a shows the Auger depth profile of a contact after the initial 1 hour anneal at $1100{ }^{\circ} \mathrm{C}$. Nickel in the alloy has reacted with the $\mathrm{SiC}$ substrate to form $\mathrm{Ni}_{\mathrm{x}} \mathrm{Si}_{\mathrm{y}}$, thus freeing the carbon that reacts with

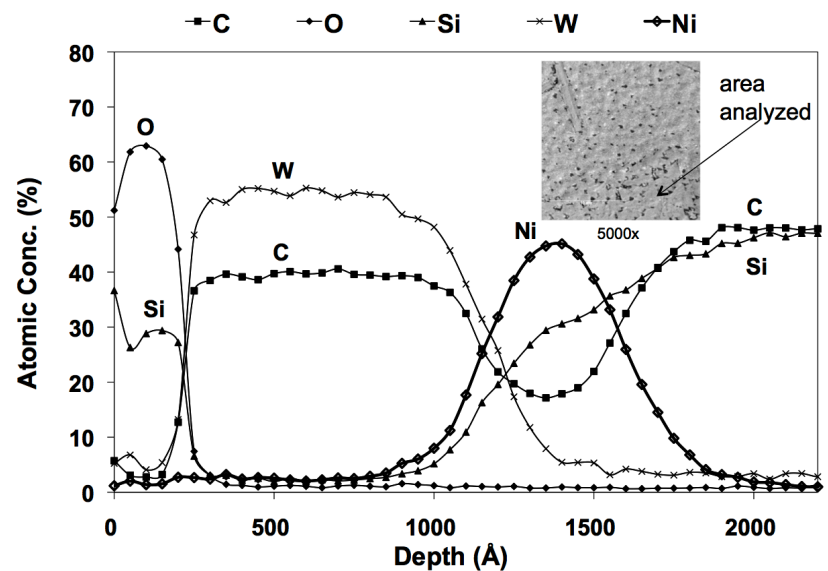

(a)

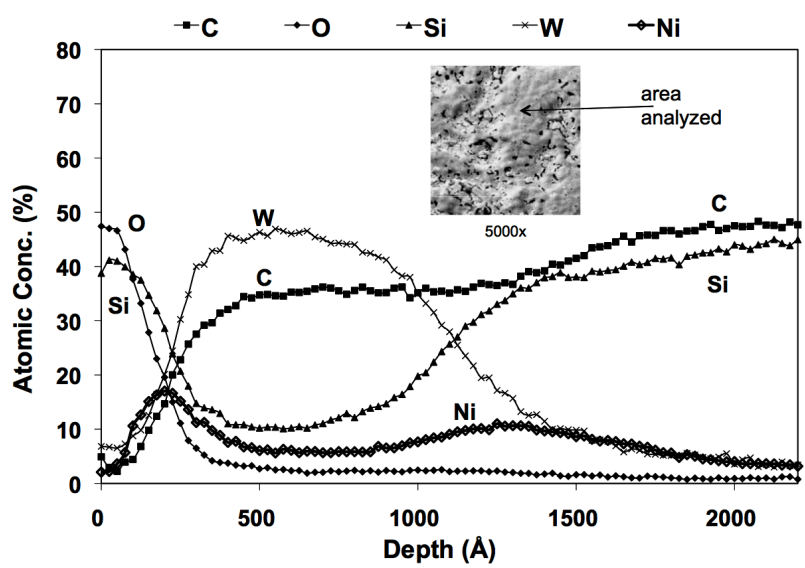

(b)

Fig. 4: (a) AES depth profile after 1 hour $1100{ }^{\circ} \mathrm{C}$ furnace anneal. (b) AES depth profile after 1 hour furnace anneal at $1100{ }^{\circ} \mathrm{C}$ and 14 hours at $1000{ }^{\circ} \mathrm{C}$.

tungsten to form $\mathrm{W}_{\mathrm{x}} \mathrm{C}_{\mathrm{y}}$. XRD analysis also showed evidence of the presence of $\mathrm{W}_{\mathrm{x}} \mathrm{Si}_{\mathrm{y}}$ compounds. The silicon oxide layer that formed on the surface during the initial anneal appears to have protected the tungsten from oxidation, maintaining approximately the same thickness while not interfering with electrical measurements. The AES of Fig. 4b shows that compounds that had formed during initial annealing remained segregated throughout the prolonged fourteen hour heating at $1000{ }^{\circ} \mathrm{C}$, 
with distinct crystalline features visible via optical microscopy. Fig. 5 shows a detailed image of the $\mathrm{SiC}$ interface after prolonged heating using HR-TEM. Nickel silicide and a matrix of tungsten silicide and carbide are observed to be in intimate contact with the SiC, making possible the formation of the stable ohmic contact.

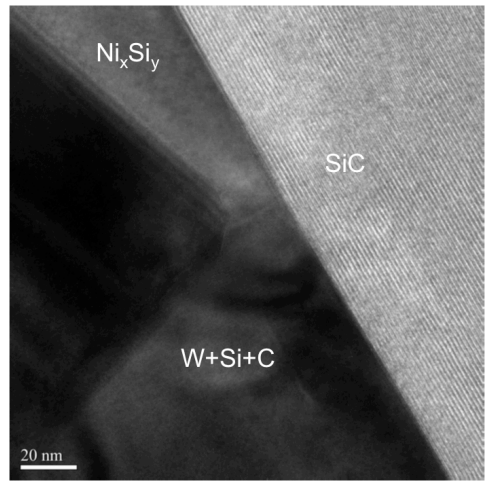

Fig. 5: HR-TEM micrograph showing formation of carbides and silicides at the $\mathrm{SiC}$ interface after high temperature anneal and prolonged heating at $1000{ }^{\circ} \mathrm{C}$ for 14 hours.

\section{Summary}

This work has demonstrated a metallization scheme with the capability to survive prolonged heating at $1000{ }^{\circ} \mathrm{C}$. This metallization scheme shows that it is possible to achieve a highly stable ohmic contact to $\mathrm{SiC}$ within the $1000{ }^{\circ} \mathrm{C}$ temperature range. It expands the capabilities for $\mathrm{SiC}$ devices as well as potentially overcoming the reliability issues that currently limit high temperature operation. Further work planned includes longer duration heating tests, as well as annealing in environments other than argon. Although results are preliminary, the data is encouraging for potential increased operation time of devices at nominal (e.g., $600{ }^{\circ} \mathrm{C}$ ) temperatures.

\section{Acknowledgements}

This work was funded by the Hypersonic Project under the Fundamental Aeronautics Program of the National Aeronautics and Space Administration (NASA). The authors greatly appreciate the contributions of A. Avishai of Case Western Reserve University for the HR-TEM analysis, C. Blaha, B. Osborn, P. Neudeck, C. Chang, G. Beheim, and L. Matus, of NASA Glenn Research Center.

\section{References}

[1] M.R. Werner, W.R. Fahrner, IEEE Transactions on Industrial Electronics, 48, 2, (2001) 249257.

[2] R.S. Okojie, P. Nguyen, V. Nguyen, E. Savrun, D. Lukco, J. Buehler, and T. McCue, Proceedings $45^{\text {th }}$ IEEE International Reliability Physics Symposium, (2007) 429-432.

[3] P.G. Neudeck, D.J. Spry, L.Y. Chen, G.M. Beheim, R.S. Okojie, C.W. Chang, R.D. Meredith, T.L. Ferrier, L.J. Evans, M.J. Krasowski, and N.F. Prokop, IEEE Electron Device Letters, 29 (2008) 456-459.

[4] S. Liu, J. Scofield, Proceedings $4^{\text {th }}$ International High Temperature Electronics Conference, (1998) 88-92.

[5] R.S. Okojie, L.J. Evans, D. Lukco, J.P. Morris, IEEE Electron Device Letters, 31, 8 (2010) 791-793.

[6] D.K. Shroder, Semiconductor Metal and Device Characterization, second ed., John Wiley \& Sons, Inc., New York, 1998.

[7] C.M. Zetterling, S.K. Lee, M. Ostling, Schottky and Ohmic Contacts to SiC, in: C.M. Zetterling (Ed.), Process Technology for Silicon Carbide Devices, Institution of Electrical Engineers, London, 2002, pp. 111-130.

[8] L.M. Porter, R.F. Davis, Materials Science and Engineering, B34 (1995) 83-105. 